\title{
Atividade de Isolados Bacterianos Solubilizadores de Fosfato na Presença de Formulações Comerciais de Glyphosate ${ }^{1}$
}

\author{
Activity of Phosphate Solubilizing Bacterial Isolates in the Presence of Commercial Glyphosate \\ Formulations
}

\begin{abstract}
MASSENSSINI, A.M. ${ }^{2}$, COSTA, M.D. ${ }^{3}$, REIS, M.R. ${ }^{4}$ e SILVA, A.A. ${ }^{5}$
RESUMO - Objetivou-se com este trabalho avaliar os efeitos da aplicação de formulações comerciais de glyphosate (Roundup Transorb ${ }^{\circledR}$, Zapp QI ${ }^{\circledR}$, Roundup NA ${ }^{\circledR}$ e Scout ${ }^{\circledR}$ ) na capacidade de dois isolados bacterianos (To 11 e To 66) em solubilizar diferentes fontes inorgânicas de fosfato. A atividade de solubilização de fosfato inorgânico dos isolados bacterianos foi avaliada em três fontes de fosfato inorgânico (fosfato de cálcio, de aluminio e de ferro), na presença de diferentes formulações de glyphosate na concentração de $60 \mathrm{mg} \mathrm{L}^{-1}$ do equivalente ácido e tratamento controle sem adição dos herbicidas. Os efeitos das formulações de glyphosate foram diferentes para cada isolado. As formulações Roundup Transorb ${ }^{\circledR}$ e Zapp QI ${ }^{\circledR}$ provocaram redução na capacidade de solubilização do isolado To 66, enquanto a formulação Scout ${ }^{\circledR}$ aumentou essa capacidade. Por sua vez, o isolado To 11 não teve sua capacidade de solubilização afetada na presença das formulações avaliadas. Em média, as formulações Roundup $\mathrm{NA}^{\circledR}$ e Scout ${ }^{\circledR}$ não alteraram a capacidade de solubilização dos isolados, ao passo que os herbicidas Roundup Transorb ${ }^{\circledR}$ e Zapp $\mathrm{QI}^{\circledR}$ reduziram essa capacidade de solubilização.
\end{abstract}

Palavras-chave: rizosfera, bactérias do solo, eucalipto.

\begin{abstract}
The objective of this work was to evaluate the effect of applying different commercial formulations of glyphosate (Roundup Transorb ${ }^{\circledR}$, Zapp QI ${ }^{\circledR}$, Roundup $N A^{\circledR}$ e Scout ${ }^{\circledR}$ ) on the ability of two bacterial isolates (To 11 and To 66) to solubilize different inorganic phosphates. The ability to solubilize bacterial isolate phosphate was evaluated in relation to three inorganic phosphate sources (calcium, aluminum, and iron phosphates) in the presence of different commercial formulations of glyphosate, at the concentration of $60 \mathrm{mg} \mathrm{L}^{-1}$ acid equivalent, and control treatment without the addition of the herbicides. The effects of the commercial formulations of glyphosate on each bacterial isolate were distinct. Roundup Transorb and Zapp QI led to a significant decrease in the phosphate-solubilizing activity of To 66, while the reverse was observed for Scout. To 11 did not show significant differences in phosphate solubilization in the presence of the commercial formulations tested. Roundup NA and Scout did not change the ability to solubilize phosphate of bacterial isolates, while Roundup Transorb and Zapp QI led to a decrease in the solubilizing activity.
\end{abstract}

Keywords: rizhosphere, soil bacteria, eucalyptus.

1 Recebido para publicação em 20.3.2008 e na forma revisada em 19.9.2008.

Parte da dissertação de Mestrado do primeiro autor (bolsista do CNPq).

2 Biólogo, Mestre em Microbiologia Agrícola, Universidade Federal de Viçosa - UFV, Viçosa-MG, 36570-000; ${ }^{3}$ D.S., Professor do Dep. de Microbiologia/UFV, <mdcosta@ufv.br>, autor para correspondência; ${ }^{4}$ Engoo-Agroํo $^{\text {, }}$ Doutorando em Fitotecnia, Dep. de Fitotecnia/UFV, ${ }^{5}$ D.S., Professor do Dep. de Fitotecnia/UFV.

Planta Daninha, Viçosa-MG, v. 26, n. 4, p. 815-823, 2008 


\section{INTRODUÇÃO}

A disponibilidade de nutrientes é um dos fatores determinantes para o desenvolvimento vegetal. No caso dos solos brasileiros, o fósforo é um dos elementos mais limitantes, e a utilização de formas solúveis para a adubação de eucalipto requer a aplicação de doses superiores às necessárias ao crescimento da planta, tendo em vista que cerca de $90 \%$ do fósforo aplicado é rapidamente adsorvido pelos oxidróxidos de Fe e Al, presentes, de modo geral, em maiores quantidades em solos tropicais mais intemperizados (Novais \& Smyth, 1999; Silva Filho et al., 2002). O íon fosfato pode também precipitar-se com íons $\mathrm{Ca}^{2+}, \mathrm{Fe}^{3+}$ e $\mathrm{Al}^{3+}$, formando compostos de composição definida e pouco solúveis (Igual et al., 2001). A solubilização dessas formas inorgânicas de fósforo é favorecida pelo consumo dos produtos solúveis, como os cátions e o íon fosfato, alterando a constante de equilíbrio (Bolan et al., 1997). Essa alteração pode ser efetuada pelas plantas e por microrganismos do solo, que são capazes de acidificar o meio, consumindo o fosfato e os cátions resultantes da solubilização. Dessa forma, a solubilização de fosfatos inorgânicos geralmente é maior na rizosfera do que em solo não-rizosférico (Bolan et al., 1997).

A importância dos microrganismos encontrados no solo rizosférico no suprimento de fósforo para as plantas já foi demonstrada em vários trabalhos (Freitas et al., 1997; Gyaneshwar et al., 2002), e sua efetividade depende da interação destes com a planta hospedeira e a microbiota associada. Esse fato é justificado pela variação que existe na composição dos exsudatos radiculares em relação à espécie da planta (Grayston et al., 1996). Aumentos na produção de matéria seca e na absorção de nutrientes por plantas de trigo em solos com baixa disponibilidade de nutrientes foram obtidos pela inoculação com bactérias solubilizadoras de fosfato e fungos micorrizicos arbusculares (Singh \& Kapoor, 1999). No entanto, vários fatores influenciam a capacidade de solubilização desses microrganismos, como a fonte de carbono e nitrogênio disponiveis (Nautiyal et al., 2000), o tipo de planta cultivada (Grayston et al., 1996), o tipo de fosfato a ser solubilizado (Nahas, 1996; Barroso \& Nahas, 2005), entre outros, como a presença de herbicidas ou inseticidas (Das \& Murkherjee, 1998; Reis et al., 2008).

O manejo das plantas daninhas em plantios de eucalipto é realizado basicamente por meio de métodos mecânicos e, em grande parte, químicos, isolados ou combinados (Toledo et al., 2003). Dos cinco herbicidas registrados para o manejo de plantas daninhas nessa cultura, o glyphosate se destaca por apresentar ótimo controle em grande número de espécies de plantas daninhas, baixo custo e baixo índice de risco ambiental (Alister \& Kogan, 2006).

Apesar da baixa biodisponibilidade do glyphosate no solo, isto é, alto coeficiente de sorção (Santos et al., 2004), e da sua aplicação dirigida em plantios de eucalipto, é possivel que ele apresente ação inibitória na atividade de bactérias solubilizadoras de fosfato em condições de campo, pois, após absorvido pela planta, o glyphosate é translocado para os meristemas apicais da planta. Nos ápices radiculares das plantas daninhas, ele pode ser exsudado e tornar-se disponível na solução do solo (Tuffi Santos et al., 2005). Desse modo, além de poder afetar a atividade microbiana associada às raízes dessas plantas, pode também afetar os microrganismos associados às raízes das plantas de eucalipto. O glyphosate é classificado como altamente tóxico aos microrganismos do solo na bula de seu produto comercial Roundup Original $^{\circledR}$; o efeito inibitório in vitro do glyphosate sobre microrganismos simbiotróficos do solo já foi relatado (Santos et al., 2004; Malty et al., 2006).

Neste trabalho, objetivou-se avaliar o efeito de diferentes formulações comerciais de glyphosate no crescimento e na atividade de isolados bacterianos solubilizadores de fosfato inorgânico obtidos de solo rizosférico de plantas de eucalipto.

\section{MATERIAL E MÉTODOS}

Para o isolamento de bactérias solubilizadoras de fosfato, foram coletadas amostras de solo rizosférico de plantas de eucalipto (Eucalyptus grandis x Eucalyptus urophylla) em povoamento com 2,5 anos de idade e espaçamento de $3 \times 3 \mathrm{~m}$, localizado no município de Viçosa, MG (S, 20 48' 07,0” e O, 42 54' 0,57 ”). As características físicas e químicas 
do solo foram: classe textural muito argilosa; pH em água de 4,86; CTC (T), CTC (t), H + Al, $\mathrm{Ca}$ e $\mathrm{Mg}$ de 11,$17 ; 1,49 ; 10,50 ; 0,17$ e $0,40 \mathrm{cmol}_{\mathrm{c}} \mathrm{dm}^{-3}$, respectivamente; P e K, respectivamente, de 2,2 e $40 \mathrm{mg} \mathrm{dm}^{-3}$; Prem de $17 \mathrm{mg} \mathrm{L}^{-1}$; e 5,50 dag $\mathrm{kg}^{-1}$ de matéria orgânica.

A partir da suspensão de $10 \mathrm{~g}$ de solo rizosférico de plantas de eucalipto em $90 \mathrm{~mL}$ de solução salina ( $\mathrm{NaCl} 0,85 \%$ ), foram preparadas diluições seriadas na mesma solução até a diluição de $10^{-5}$. Alíquotas de $0,1 \mathrm{~mL}$ das diluições $10^{-3}, 10^{-4}$ e $10^{-5}$ foram inoculadas na superficie do meio NBRIP sólido, suplementado com fosfato de cálcio (Nautiyal, 1999). Após sete dias de incubação a $30^{\circ} \mathrm{C}$, as bactérias solubilizadoras de fosfato inorgânico foram selecionadas pela presença de halos de solubilização em torno da colônia.

Cada isolado foi inoculado na superficie do meio NBRIP sólido e incubado por sete dias a $30{ }^{\circ} \mathrm{C}$. Posteriormente, determinou-se o índice de solubilização (IS) de fosfato de cálcio, dividindo-se o diâmetro do halo pelo diâmetro da colônia, conforme descrito por Kumar \& Narula (1999), sendo classificados em baixa (IS < 2), média $(2<$ IS < 3) e alta solubilização (IS > 3) (Silva Filho \& Vidor, 2000).

O crescimento de dois isolados de cada classe (alta, média e baixa capacidade de solubilização de fosfato inorgânico) foi avaliado na presença das formulações comerciais: Roundup Transorb ${ }^{\circledR}$, Roundup $\mathrm{NA}^{\circledR}$, Zapp $\mathrm{QI}^{\circledR} \mathrm{e}$ Scout $^{\circledR}$, na dose de $60 \mathrm{mg} \mathrm{L}^{-1}$ do equivalente ácido (glyphosate) - correspondente à dose comercial recomendada. Um tratamento sem herbicida para cada isolado também foi incluído. O experimento foi conduzido em placas de Elisa contendo $150 \mu \mathrm{L}$ de meio Caldo Nutriente, suplementado com as diferentes doses dos herbicidas, e inoculadas com células previamente cultivadas por $12 \mathrm{~h}$ a $30^{\circ} \mathrm{C}$ em meio Caldo Nutriente. As placas foram incubadas a $30{ }^{\circ} \mathrm{C}$ por $48 \mathrm{~h}$, e o crescimento dos isolados foi avaliado em intervalos de uma hora por meio da densidade óptica a $560 \mathrm{~nm}$. Os dados de absorvância foram ajustados de acordo com o modelo logístico (Drapper, 1981), e os coeficientes das regressões foram comparados utilizando o teste $\mathrm{F}$ a $5 \%$ de probabilidade.

$\mathrm{Na}$ presença de herbicidas, determinouse a atividade de solubilização de fosfato dos isolados To 66 e To 11, que apresentaram maior e menor sensibilidade ao herbicida, respectivamente, na presença de diferentes fontes inorgânicas de fosfato. Os isolados foram inoculados em $50 \mathrm{~mL}$ de meio NBRIP líquido (Nautiyal, 1999), com adição de diferentes fontes inorgânicas de fósforo $\left(\mathrm{Ca}_{5} \mathrm{P}_{3} \mathrm{HO}_{13}, \mathrm{FePO}_{4}\right.$ ou $\mathrm{AlPO}_{4}$ ), em quantidade equivalente a $5 \mathrm{~g}$ de $\mathrm{P} \mathrm{L}^{-1}$, suplementado com diferentes formulações comerciais: Roundup Transorb ${ }^{\circledR}$, Roundup $\mathrm{NA}^{\circledR}$, Zapp $\mathrm{QI}^{\circledR}$ e Scout $^{\circledR}$, na dose de $60 \mathrm{mg} \mathrm{L}^{-1}$ do equivalente ácido (glyphosate) e controle sem inoculação, em frascos erlenmeyers de $125 \mathrm{~mL}$ a $30^{\circ} \mathrm{C}$ e $200 \mathrm{rpm}$ por três dias, com três repetições. Um tratamento controle sem adição de fosfato foi também incluído. A inoculação foi realizada por meio de uma alçada, transferindo-se células previamente cultivadas por $12 \mathrm{~h}$ a $30^{\circ} \mathrm{C}$ em tubos de Ágar Nutriente inclinado. Após período de incubação, determinou-se o fósforo solúvel pelo método colorimétrico descrito por Braga \& De Felipo (1974). Os dados foram submetidos à análise de variância e as médias comparadas pelo teste de Tukey a $5 \%$ de probabilidade.

\section{RESULTADOS E DISCUSSÃO}

Foram obtidos 66 isolados bacterianos formadores de halo de solubilização. Os isolados diferiram quanto à capacidade de solubilizar fosfato de cálcio in vitro, apresentando índices de solubilização (IS) entre 0 , relativo aos microrganismos que perderam a capacidade de solubilização, e 4,07. Dos 43 isolados bacterianos restantes, a maioria apresentou IS variando de 0 a 2,17, com exceção dos isolados To 1 , To 7 e To 47, que apresentaram índices superiores a 3,15 (dados não apresentados). Variações no potencial de solubilização de fosfato por microrganismos têm sido observadas por vários autores (Silva Filho \& Vidor, 2000). De acordo com a classificação proposta por Silva Filho \& Vidor (2000), os isolados To 7 e To 47 apresentaram alta solubilização; To 3 e To 66, média solubilização; e os demais, baixa solubilização.

As diferentes formulações comerciais de glyphosate afetaram o crescimento dos isolados bacterianos testados. Na presença das diferentes formulações, verificou-se redução da taxa de crescimento dos isolados bacterianos, 
expressa como diminuição na inclinação das curvas durante a fase log, cuja duração foi reduzida na presença dos herbicidas em comparação à testemunha sem aplicação de herbicidas (Figura 1 e Tabela 1). Os isolados mais afetados pela presença das diferentes formulações comerciais de glyphosate foram o To 7 , To 47, To 66 e To 3, que tiveram, de modo geral, maiores reduções no seu crescimento. Por sua vez, os isolados To 32 e To 11 (baixa solubilização) apresentaram pequenas reduções no crescimento (Figura 1 e Tabela 1). O crescimento do isolado To 47 foi mais afetado em relação aos demais, independentemente da formulação de glyphosate adicionada ao meio.

As formulações Scout ${ }^{\circledR}$ e Zapp QI ${ }^{\circledR}$, em geral, reduziram o crescimento dos isolados de forma branda, e a formulação Roundup $\mathrm{NA}^{\circledR}$, de forma moderada. Por outro lado, a formulação Roundup Transorb ${ }^{\circledR}$ reduziu drasticamente o crescimento dos isolados; os isolados de alta e média solubilização - To 47 e To 66, respectivamente - tiveram seu crescimento reduzido pela metade (Tabela 2 ).

De acordo com os modelos de regressão (Tabela 1) e a comparação das médias após $48 \mathrm{~h}$ de incubação (Tabela 2), estabeleceu-se uma ordem decrescente das formulações de glyphosate em relação à sua toxicidade aos isolados: Roundup Transorb ${ }^{\circledR}>$ Roundup $\mathrm{NA}^{\circledR}>$ Zapp $\mathrm{QI}^{\circledR}>$ Scout $^{\circledR}$. Ao avaliar o efeito de diferentes formulações comerciais de glyphosate sobre estirpes de Bradyrhizobium, Santos et al. (2004) verificaram que a formulação Roundup Transorb ${ }^{\circledR}$ provocou maior intoxicação nas estirpes avaliadas. Também, observaram o comportamento diferenciado entre as estirpes estudadas cultivadas na presença das formulações. O efeito tóxico das formulações de glyphosate foi associado às diferentes substâncias químicas presentes nas formulações, como solventes, surfatantes e agentes molhantes, que podem modificar a ação do equivalente ácido glyphosate (padrão de N-(phosphomethyl) glycina) (Malkones, 2000).

Os isolados apresentaram diferenças na capacidade de solubilização na presença das diferentes fontes de fosfato inorgânico (Tabela 3). O isolado To 66 apresentou, em média, maior solubilização de fosfato de cálcio do que o To 11. Todavia, nenhum deles foi capaz de solubilizar os fosfatos de ferro e aluminio. Esse fato pode ser explicado pelo $\mathrm{pH}$ final do meio de cultura, que geralmente foi mais baixo na presença dos fosfatos de ferro e alumínio (dados não mostrados). A solubilização de fosfato pela liberação de ácidos orgânicos acidifica o meio e, em condições de baixo $\mathrm{pH}$, os compostos formados pela precipitação de fósforo com os íons de ferro e aluminio tornamse mais estáveis (Novais \& Smyth, 1999). Por outro lado, os compostos da precipitação de fósforo e o íon cálcio apresentam maior solubilidade nessas condições.

Os isolados mostraram comportamentos diferenciados na presença das diferentes formulações comerciais de glyphosate. A capacidade de solubilização do isolado To 66 foi afetada na presença das diferentes formulações de glyphosate, cuja solubilização média foi de 2223,65 $\mu \mathrm{g}$ de $\mathrm{P}$, enquanto o isolado To 11 não apresentou alterações significativas (Tabela 3). $\mathrm{Na}$ presença do herbicida Scout ${ }^{\circledR}$, o isolado To 66 teve sua capacidade de solubilização aumentada, porém não houve alteração na presença do herbicida Roundup $\mathrm{NA}^{\circledR}$. Por sua vez, os herbicidas Roundup Transorb ${ }^{\circledR}$ e Zapp QI ${ }^{\circledR}$ provocaram redução significativa na capacidade de solubilização deste isolado. Observa-se, então, que a presença do glyphosate não é o único fator responsável pelas alterações na capacidade de solubilização do isolado To 66, uma vez que houve diferenças marcantes, dependendo da formulação comercial testada (Tabela 3). Esse fato sugere que outros compostos presentes nas formulações, atuando isoladamente ou em combinação com o glyphosate, são capazes de alterar o comportamento fisiológico do isolado, afetando, assim, sua capacidade de solubilização.

$\mathrm{Na}$ presença das formulações comerciais de glyphosate, verificou-se que o isolado To 66, que se mostrou mais sensivel ao herbicida quanto ao crescimento, foi o que apresentou maior alteração no potencial de solubilização, não sendo observado um padrão muito claro, visto que todas as formulações reduziram o crescimento do isolado; entretanto, apenas duas reduziram significantemente o seu potencial de solubilização. Por outro lado, o isolado To 11, que apresentou reduções brandas no crescimento na presença das formulações 

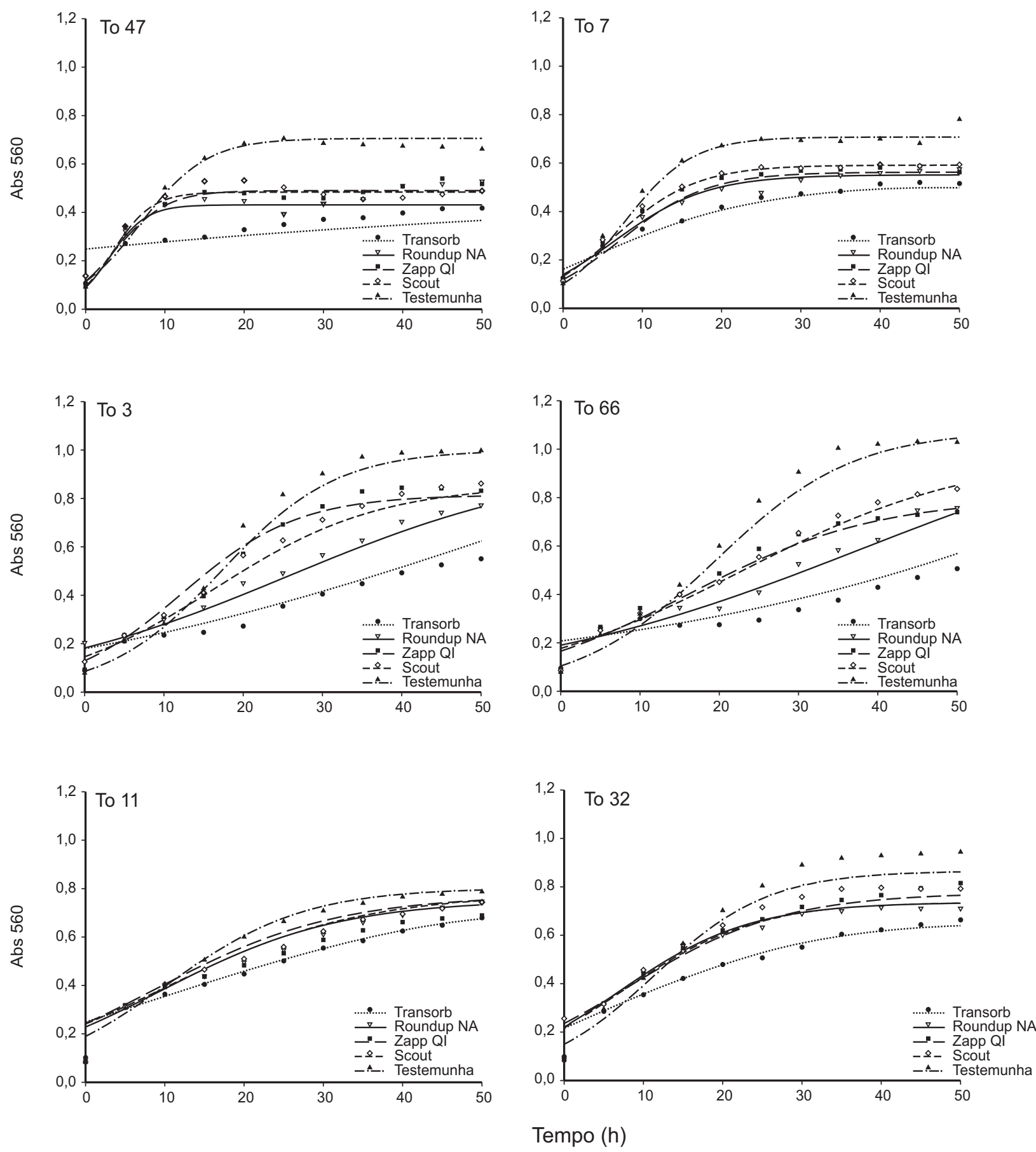

Figura 1 - Curvas de crescimento de bactérias isoladas da rizosfera do híbrido Eucalyptus grandis x Eucalyptus urophylla, cultivadas em meio Caldo Nutriente por $48 \mathrm{~h}$ a $30{ }^{\circ} \mathrm{C}$, na presença de diferentes formulações comerciais de glyphosate (60 $\mathrm{mg} \mathrm{L}^{-1}$ de e.a.) - média de três repetições. Viçosa, 2007. 
Tabela 1 - Equações ajustadas relacionando a densidade óptica (Abs 560) e o tempo de incubação (h), para diferentes formulações comerciais de glyphosate $\left(60 \mathrm{mg} \mathrm{L}^{-1}\right.$ de e.a.) testadas sobre o crescimento de bactérias isoladas da rizosfera do híbrido Eucalyptus grandis $\mathrm{x}$ Eucalyptus urophylla. Viçosa, 2007

\begin{tabular}{|c|c|c|}
\hline Tratamento & Equação ajustada & $\mathrm{R}^{2}$ \\
\hline & To 47 & \\
\hline Transorb & $\hat{\mathrm{Y}}=0,4342 /\left(1+0,7591 \cdot \mathrm{e}^{-0,0286 \mathrm{X}}\right)$ & 0,9124 \\
\hline Roundup NA & $\hat{\mathrm{Y}}=0,4310 /\left(1+3,8053 . \mathrm{e}^{-0,4369 \mathrm{X}}\right)$ & 0,7409 \\
\hline Zapp QI & $\hat{\mathrm{Y}}=0,4899 /\left(1+3,2429 . \mathrm{e}^{-0,3106 \mathrm{X}}\right)$ & 0,8895 \\
\hline Scout & $\hat{\mathrm{Y}}=0,4837 /\left(1+4,1207 \cdot \mathrm{e}^{-0,4056 \mathrm{X}}\right)$ & 0,7312 \\
\hline \multirow[t]{2}{*}{ Testemunha sem herbicida } & $\hat{\mathrm{Y}}=0,7056 /\left(1+5,1498 \cdot \mathrm{e}^{-0,2317 \mathrm{X}}\right)$ & 0,9856 \\
\hline & To 7 & \\
\hline Transorb & $\hat{\mathrm{Y}}=0,5516 /\left(1+2,9647 \cdot \mathrm{e}^{-0,1702 \mathrm{X}}\right)$ & 0,9867 \\
\hline Roundup NA & $\hat{\mathrm{Y}}=0,5624 /\left(1+3,7552 \cdot \mathrm{e}^{-0,1828 \mathrm{X}}\right)$ & 0,9940 \\
\hline Zapp QI & $\hat{\mathrm{Y}}=0,5913 /\left(1+3,4657 \cdot \mathrm{e}^{-0,1917 \mathrm{X}}\right)$ & 0,9895 \\
\hline Scout & $\hat{\mathrm{Y}}=0,7074 /\left(1+6,0277 . \mathrm{e}^{-0,2335 \mathrm{X}}\right)$ & 0,9942 \\
\hline \multirow[t]{2}{*}{ Testemunha sem herbicida } & $\hat{\mathrm{Y}}=0,7074 /\left(1+6,0277 . \mathrm{e}^{-0,2335 \mathrm{X}}\right)$ & 0,9942 \\
\hline & To 3 & \\
\hline Transorb & $\hat{\mathrm{Y}}=1,1027 /\left(1+5,1319 \cdot \mathrm{e}^{-0,0379 \mathrm{X}}\right)$ & 0,9840 \\
\hline Roundup NA & $\hat{\mathrm{Y}}=0,9581 /\left(1+4,2532 \cdot \mathrm{e}^{-0,0564 \mathrm{X}}\right)$ & 0,9926 \\
\hline Zapp QI & $\hat{\mathrm{Y}}=0,8143 /\left(1+5,2909 \cdot \mathrm{e}^{-0,1358 \mathrm{X}}\right)$ & 0,9934 \\
\hline Scout & $\hat{\mathrm{Y}}=0,8553 /\left(1+4,8570 . \mathrm{e}^{-0,0963 \mathrm{X}}\right)$ & 0,9953 \\
\hline \multirow[t]{2}{*}{ Testemunha } & $\hat{\mathrm{Y}}=0,9999 /\left(1+10,6806 \cdot \mathrm{e}^{-0,1373 \mathrm{X}}\right)$ & 0,9938 \\
\hline & To 66 & \\
\hline Transorb & $\hat{Y}=2764,61 /\left(1+13380,44 . \mathrm{e}^{-0,0203 \mathrm{X}}\right)$ & 0,9778 \\
\hline Roundup NA & $\hat{\mathrm{Y}}=1,1742 /\left(1+5,1751 \cdot \mathrm{e}^{-0,0434 \mathrm{X}}\right)$ & 0,9764 \\
\hline Zapp QI & $\hat{\mathrm{Y}}=0,7993 /\left(1+3,8291 . \mathrm{e}^{-0,0837 \mathrm{X}}\right)$ & 0,9967 \\
\hline Scout & $\hat{\mathrm{Y}}=0,9862 /\left(1+4,5728 \cdot \mathrm{e}^{-0,0672 \mathrm{X}}\right)$ & 0,9949 \\
\hline \multirow[t]{2}{*}{ Testemunha sem herbicida } & $\hat{\mathrm{Y}}=1,0771 /\left(1+9,3186 \cdot \mathrm{e}^{-0,1146 \mathrm{X}}\right)$ & 0,9954 \\
\hline & To 11 & \\
\hline Transorb & $\hat{\mathrm{Y}}=0,7545 /\left(1+2,0123 \cdot \mathrm{e}^{-0,0568 \mathrm{X}}\right)$ & 0,9943 \\
\hline Roundup NA & $\hat{\mathrm{Y}}=0,7531 /\left(1+2,3022 . \mathrm{e}^{-0,0885 \mathrm{X}}\right)$ & 0,9944 \\
\hline Zapp QI & $\hat{Y}=0,7227 /\left(1+2,1776 \cdot \mathrm{e}^{-0,0873 X}\right)$ & 0,9932 \\
\hline Scout & $\hat{\mathrm{Y}}=0,7798 /\left(1+2,2370 . \mathrm{e}^{-0,0808 \mathrm{X}}\right)$ & 0,9948 \\
\hline \multirow[t]{2}{*}{ Testemunha sem herbicida } & $\hat{\mathrm{Y}}=0,8023 /\left(1+3,2295 \cdot \mathrm{e}^{-0,1148 \mathrm{X}}\right)$ & 0,9968 \\
\hline & To 32 & \\
\hline Transorb & $\hat{\mathrm{Y}}=0,6595 /\left(1+1,9924 \cdot \mathrm{e}^{-0,0830 \mathrm{X}}\right)$ & 0,9742 \\
\hline Roundup NA & $\hat{\mathrm{Y}}=0,7362 /\left(1+2,3186 \cdot \mathrm{e}^{-0,1212 \mathrm{X}}\right)$ & 0,9906 \\
\hline Zapp QI & $\hat{\mathrm{Y}}=0,7757 /\left(1+2,2908 \cdot \mathrm{e}^{-0,1019 \mathrm{X}}\right)$ & 0,9850 \\
\hline Scout & $\hat{\mathrm{Y}}=0,7382 /\left(1+2,3839 . \mathrm{e}^{-0,1190 \mathrm{X}}\right)$ & 0,9899 \\
\hline Testemunha sem herbicida & $\hat{\mathrm{Y}}=0,8658 /\left(1+4,7832 \cdot \mathrm{e}^{-0,1379 \mathrm{X}}\right)$ & 0,9972 \\
\hline
\end{tabular}


Tabela 2 - Crescimento relativo de bactérias isoladas da rizosfera do híbrido Eucalyptus grandis x Eucalyptus urophylla na presença de diferentes formulações comerciais de glyphosate (60 $\mathrm{mg} \mathrm{L}^{-1}$ de e.a.), após $48 \mathrm{~h}$ de incubação em meio Caldo Nutriente a $30{ }^{\circ} \mathrm{C}$. Viçosa, 2007

\begin{tabular}{|c|c|c|c|c|c|c|}
\hline \multirow{2}{*}{ Tratamento } & \multicolumn{6}{|c|}{ Abs $560(\%)$} \\
\hline & To 47 & To 7 & To 3 & To 66 & To 11 & To 32 \\
\hline Testemunha & $100,00^{1 /} \mathrm{aA}$ & $100,00 \mathrm{aA}$ & $100,00 \mathrm{aA}$ & $100,00 \mathrm{aA}$ & $100,00 \mathrm{aA}$ & $100,00 \mathrm{aA}$ \\
\hline Scout & $70,17 \mathrm{bcC}$ & $89,30 \mathrm{bAB}$ & $83,70 \mathrm{bB}$ & $82,55 \mathrm{bB}$ & $92,87 \mathrm{bA}$ & $82,99 \mathrm{cdB}$ \\
\hline Zapp QI & $76,27 \mathrm{bCD}$ & $82,20 \mathrm{cBC}$ & $80,49 \mathrm{bC}$ & $73,40 \mathrm{cD}$ & $88,69 \mathrm{bcAB}$ & $91,13 \mathrm{bA}$ \\
\hline Roundup NA & $63,93 \mathrm{cD}$ & $80,11 \mathrm{cBC}$ & $78,16 \mathrm{bC}$ & $69,66 \mathrm{cD}$ & $90,89 \mathrm{bA}$ & $86,71 \mathrm{bcAB}$ \\
\hline Transorb & $51,12 \mathrm{dD}$ & $70,33 \mathrm{dBC}$ & $68,14 \mathrm{cC}$ & $53,08 \mathrm{dD}$ & $82,13 \mathrm{cA}$ & $76,52 \mathrm{dAB}$ \\
\hline
\end{tabular}

${ }^{1 /}$ Médias seguidas pelas mesmas letras minúsculas nas colunas e maiúsculas nas linhas não diferem estatisticamente entre si pelo teste de Tukey $(\mathrm{P} \leq 0,05)$.

Tabela 3 - Fósforo solubilizado, em $\mu \mathrm{g}$ de $\mathrm{P}$, por isolados bacterianos da rizosfera de eucalipto (Eucalyptus grandis x Eucalyptus urophylla) e cultivados em meio NBRIP, suplementado com diferentes formulações comerciais de glyphosate $\left(60 \mathrm{mg} \mathrm{L}^{-1}\right.$ de e.a.), por três dias a $30{ }^{\circ} \mathrm{C}$, na presença de fosfato de cálcio, ferro ou alumínio. Viçosa, 2007

\begin{tabular}{|c|c|c|c|c|}
\hline \multirow{2}{*}{ Tratamento } & \multicolumn{4}{|c|}{ To 66} \\
\hline & $\mathrm{Ca}_{5} \mathrm{P}_{3} \mathrm{HO}_{13}$ & $\mathrm{FePO}_{4}$ & $\mathrm{AlPO}_{4}$ & Média \\
\hline Roundup Transorb $^{\circledR}$ & $2363,54 \mathrm{Ca}^{1 /}$ & $32,57 \mathrm{Ab} \alpha$ & $128,00 \mathrm{Ab} \alpha$ & $841,37 \mathrm{Ca}$ \\
\hline Zapp QI $^{\text {B }}$ & $178,51 \mathrm{Ca} \alpha$ & $28,07 \mathrm{Aa} \alpha$ & $129,20 \mathrm{Aa} \alpha$ & $111,93 \mathrm{Ca}$ \\
\hline Roundup NA $^{(B)}$ & $7364,47 \mathrm{Ba} \alpha$ & $58,94 \mathrm{Ab} \alpha$ & $201,56 \mathrm{Ab} \alpha$ & $2541,66 \mathrm{Ba}$ \\
\hline Scout $^{(B)}$ & $14063,78 \mathrm{Aa} \alpha$ & $39,89 \mathrm{Ab} \alpha$ & $89,16 \mathrm{Ab} \alpha$ & $4730,94 \mathrm{Aa}$ \\
\hline Testemunha sem herbicida & $8011,92 \mathrm{Ba} \alpha$ & $43,46 \mathrm{Ab} \alpha$ & $621,72 \mathrm{Ab} \alpha$ & $2892,37 \mathrm{Ba}$ \\
\hline \multirow[t]{2}{*}{ Média } & $6396,45 \mathrm{Aa}$ & $40,59 \mathrm{Ba}$ & $233,93 \mathrm{Ba}$ & $2223,65 \mathrm{~A}$ \\
\hline & \multicolumn{4}{|c|}{ To 11} \\
\hline Roundup Transorb $^{\circledR}$ & $1078,80 \mathrm{Aa} \alpha \beta$ & $26,70 \mathrm{Aa} \alpha$ & $93,09 \mathrm{Aa} \alpha$ & $399,53 \mathrm{Aa}$ \\
\hline Zapp QI $^{\circledR}$ & $1214,57 \mathrm{Aa} \alpha$ & $30,93 \mathrm{Aa} \alpha$ & $105,62 \mathrm{Aa} \alpha$ & $450,37 \mathrm{Aa}$ \\
\hline Roundup NA $^{\circledR}$ & $1058,13 \mathrm{Aa} \beta$ & $30,17 \mathrm{Aa} \alpha$ & $130,78 \mathrm{Aa} \alpha$ & $406,36 \mathrm{Ab}$ \\
\hline Scout $^{(B)}$ & $1241,64 \mathrm{Aa} \beta$ & $34,43 \mathrm{Aa} \alpha$ & $169,79 \mathrm{Aa} \alpha$ & $481,95 \mathrm{Ab}$ \\
\hline Testemunha sem herbicida & $2633,99 \mathrm{Aa} \beta$ & $106,18 \mathrm{Ab} \alpha$ & $348,29 \mathrm{Ab} \alpha$ & $1029,49 \mathrm{Ab}$ \\
\hline \multirow[t]{2}{*}{ Média } & $1445,43 \mathrm{Ab}$ & $45,68 \mathrm{Ba}$ & $169,51 \mathrm{Ba}$ & $553,54 \mathrm{~B}$ \\
\hline & \multicolumn{4}{|c|}{ Controle $^{3 /}$} \\
\hline Roundup Transorb $\left.^{(}\right)$ & $144,94 \mathrm{Aa} \beta$ & $33,30 \mathrm{Aa} \alpha$ & $216,18 \mathrm{Aa} \alpha$ & $131,47 \mathrm{Aa}$ \\
\hline Zapp $\mathrm{QI}^{\circledR}$ & $220,00 \mathrm{Aa} \alpha$ & $55,68 \mathrm{Aa} \alpha$ & $217,27 \mathrm{Aa} \alpha$ & $164,32 \mathrm{Aa}$ \\
\hline Roundup NA $^{(B)}$ & $143,03 \mathrm{Aa} \beta$ & $40,40 \mathrm{Aa} \alpha$ & 178,79 Аа $\alpha$ & $120,74 \mathrm{Ab}$ \\
\hline Scout $^{B}$ & $137,30 \mathrm{Aa} \beta$ & $35,21 \mathrm{Aa} \alpha$ & $206,63 \mathrm{Aa} \alpha$ & $125,38 \mathrm{Ab}$ \\
\hline Testemunha sem herbicida & 61,64 Aa $\gamma$ & $52,95 \mathrm{Aa} \alpha$ & $206,63 \mathrm{Aa} \alpha$ & $107,09 \mathrm{Ab}$ \\
\hline Média & $141,39 \mathrm{Ac}$ & $43,51 \mathrm{Aa}$ & $204,50 \mathrm{Aa}$ & $129,80 \mathrm{~B}$ \\
\hline
\end{tabular}

${ }^{1 /} \mathrm{Na}$ coluna, valores seguidos da mesma letra maiúscula não diferem entre si pelo teste de Tukey $(\mathrm{P} \leq 0,05)$. Na linha, valores seguidos da mesma letra minúscula não diferem entre si pelo teste de Tukey $(\mathrm{P} \leq 0,05)$. Entre os isolados, valores do mesmo tratamento seguidos por letras gregas iguais não diferem entre si pelo teste de Tukey $(\mathrm{P} \leq 0,05)$. Para as médias, valores seguidos da mesma letra maiúscula não diferem entre si pelo teste de Tukey $(\mathrm{P} \leq 0,05)$ para os mesmos isolados. Entre os isolados, valores seguidos da mesma letra minúscula não diferem entre si pelo teste de Tukey $(\mathrm{P} \leq 0,05)$.

2/ Controle sem inoculação. 
testadas, não foi afetado significativamente quanto ao potencial de solubilização.

Conclui-se que, independentemente da formulação comercial de glyphosate presente, o crescimento e a atividade das bactérias solubilizadoras de fosfato inorgânico da rizosfera de eucalipto são afetados de forma diferenciada. Entre as diferentes formulações comerciais de glyphosate, a Roundup Transorb ${ }^{\circledR}$ foi mais prejudicial às bactérias solubilizadoras de fosfato inorgânico testadas.

\section{AGRADECIMENTOS}

Ao CNPq, pela concessão da bolsa ao primeiro autor.

\section{LITERATURA CITADA}

ALISTER, C.; KOGAN, M. ERI: Environmental risk index. A simple proposal to select agrochemicals for agricultural use. Crop Prot., v. 25, n. 3, p. 202-211, 2006.

BARROSO, C. B.; NAHAS, E. The status of soil phosphate fractions and the ability of fungi to dissolve hardly soluble phosphates. Appl. Soil Ecol., v. 29, n. 1, p. 73-83, 2005.

BOLAN, N. S. et al. Enhanced dissolution of phosphate rocks in the rhizosphere. Biol. Fert. Soils, v. 24, n. 2, p. 169-174, 1997.

BRAGA, J. M.; DEFELIPO, B. V. Determinação espectrofotométrica de fósforo em extratos de solos e plantas. R. Ceres, v. 21, n. 113, p. 73-85, 1974.

DAS, A. C.; MURKHERJEE, D. Insecticidal effects on soil microorganisms and their biochemical processes related to soil fertility. World J. Microbiol. Biotechnol., v. 14, n. 6, p. 903-909, 1998.

DRAPER, N. R. Applied regression analysis. 2.ed. New York: John Wiley, 1981. 709 p.

FREITAS, J. R.; BANERJEE, M. R.; GERMIDA, J. J. Phosphate solubilizing rhizobacteria enhance the growth and yield but not uptake of canola (Brassica napus L.). Biol.

Fert. Soils, v. 24, n. 4, p. 358-364, 1997.

GRAYSTON, S. J.; VAUGHAN, D.; JONES, D.

Rhizosphere carbon flow in trees, in comparison with annual plants: The importance of root exudation and its impact on microbial activity and nutrient availability. Appl. Soil Ecol., v. 5, n. 1, p. 29-56, 1996.

GYANESHWAR, P. et al. Role of soil microorganisms in improving P nutrition of plants. Plant Soil, v. 245, n. 1, p. 83-93, 2002.
IGUAL, J. M. et al. Phosphate-solubilizing bacteria as inoculants for agriculture: Use of updated molecular techniques in their study. Agronomie, v. 21, p. 561-568, 2001.

KUMAR, V.; NARULA, N. Solubilization of inorganic phosphates and growth emergence of wheat as affected by Azotobacter chroococcum mutants. Biol. Fert. Soils, v. 28 , n. 3, p. 301-305, 1999.

MALKONES, H. P. Comparison of the effects of differently formulated herbicides on soil microbial activities - A review. J. Plant Disease Protect, v. 8, n. 5, p. 781-789, 2000.

MALTY, J. S.; SIQUEIRA, J. O.; MOREIRA, F. M. S. Efeitos do glifosato sobre microrganismos simbiotróficos de soja, em meio de cultura e casa de vegetação. Pesq. Agropec. Bras., v. 41, n. 2, p. 285-291, 2006.

NAHAS, E. Factors determining rock phosphate solubilization by microorganisms isolated from soil. World J. Microbiol. Biotecnol., v. 12, n. 6, p. 567-572, 1996.

NAUTIYAL, C. S. An effect microbiological growth medium for screening phosphate solubilizing microorganisms. FEMS Microbiol. Letters, v. 170, n. 1, p. 265-270, 1999.

NAUTIYAL, C. S. et al. Stress induced phosphate solubilization in bacteria isolated from alkaline soils. FEMS Microbiol Lett, v. 182, p. 291-296, 2000.

NOVAIS, R. F.; SMYTH, T. J. Adsorção de fósforo no solo. In: NOVAIS, R. F.; SMYTH, T. J. (Eds.). Fósforo em solo e planta em condições tropicais. Viçosa-MG: Universidade Federal de Viçosa, 1999. p. 59-95.

REIS, M. R. et al. Ação de herbicidas sobre microrganismos solubilizadores de fosfato inorgânico de solo rizosférico de cana-de-açúcar. Planta Daninha, v. 26, n. 2, p. 333-341, 2008.

SANTOS, J. B. et al. Efeitos de diferentes formulações comerciais de glyphosate sobre estirpes de Bradyrhizobium. Planta Daninha, v. 22, n. 2, p. 293-299, 2004

SILVA FILHO, G. N.; VIDOR, C. Solubilização de fosfatos por microrganismos na presença de fontes de carbono. R. Bras. Ci. Solo, v. 24, n. 2, p. 311-319, 2000.

SILVA FILHO, G. N.; NARLOCH, C.; SCHARF, R. Solubilização de fosfatos naturais por microrganismos isolados de cultivos de Pinus e Eucalyptus de Santa Catarina. Pesq. Agropec. Bras., v. 37, n. 6, p. 847-854, 2002.

SINGH, S.; KAPOOR, K. K. Inoculation with phosphate solubilizing microorganisms and a vesicular-arbuscular mycorrhizal fungus improves dry matter yield and nutrient uptake by wheat grown in a sandy soil. Biol. Fert. Soils, v. 28 , n. 2, p. 139-144, 1999. 
TOLEDO, R. E. B. et al. Faixas de controle de plantas daninhas e seus reflexos no crescimento de plantas de eucalipto. Sci. For., v. 64, n. 1, p. 78-92, 2003.
TUFFI SANTOS, L. D. et al. Exsudação radicular do glyphosate por Brachiaria decumbens e seus efeitos em plantas de eucalipto e na respiração microbiana do solo. Planta Daninha, v. 23, n. 1, p. 143-152, 2005 